\title{
Global Biodiversity of Insects: Main Trends of Study, to the Question of Method and Importance of Research
}

\section{Margarita G Ponomarenko}

Institute of Biology and Soil Sciences of Far Eastern Branch of Russian Academy of Sciences, Far Eastern Federal University, Vladivostok, Russia

*Corresponding author: Margarita G Ponomarenko, Institute of Biology and Soil Sciences of Far Eastern Branch of Russian Academy of Sciences, Far Eastern Federal University, Vladivostok, Russia, Tel: + 7-4232- 311-133; E-mail: margp@ibss.dvo.ru

Received date: Apr 09, 2014, Accepted date: May 21, 2014, Publication date: May 29, 2014

Copyright: (c) 2014 Ponomarenko MG. This is an open-access article distributed under the terms of the Creative Commons Attribution License, which permits unrestricted use, distribution, and reproduction in any medium, provided the original author and source are credited.

\begin{abstract}
The main directions in insect biodiversity study are outlined on the base of analysis of entomological publications. There are three trends, each of which is determined by method used for research. The present paper concerns problem of importance of molecular method and its place in methodology used by taxonomy. Significance of biodiversity investigation and its structuring, as well as necessity of expert assessment are discussed.
\end{abstract}

Keywords: Biodiversity; Insects; Morphological method; Molecular method; Integrative taxonomy.

\section{Introduction}

Insects is colossal numerically group, included an estimated from 6 to 10 million species, and the number of their known species is more than $58 \%$ of global biodiversity [1]. To this day the study of entomofauna of different parts of the Earth significantly replenishes insect biodiversity, and rate of new taxa description only increased in recent years. This is greatly stimulated by the development of new, high-tech method of species identification, which is the DNA barcoding program, claiming not only to catalogue of all global biodiversity, but also deal with a series of difficult taxonomic problems. The generous financing of a number of large international projects and programs aimed at DNA barcoding is indicative of lively interest to the new technology.

However, the study of biodiversity of various regions is not limited only by making an inventory of species. Global biodiversity is needed to be ordered and systematized. Taxonomic structuring of biodiversity not only insects, but also of all terrestrial organisms basing on the detection and hierarchical subordination of monophyletic groups is one of the priority tasks of modern biology. And it seemingly taxonomists will not have to complain of a lack of work for a long time. However, the situation is completely different: the number of experienced taxonomists, experts in systematics, capable of firsthandly identify species and revise complicated terrestrial organisms, to develop a natural system based on phylogenetic analysis of group and to structure of studied biodiversity, is less and less every year. What's the matter? The author sees the answer in a sudden change of tempo of modern life and the demands of society. Currently continuous routine and hard work of taxonomist with difficult anticipated result becomes unattractive by complexity and (not afraid appraisal) by covering of expenditure financially. Now, with the breakthrough of new technology in the Entomology of 21st century it has become possible to analyze a large number of samples of target genomic DNA fragments of any group of insects in a short time and obtain information about not only taxonomic diversification of the group, but also phylogram with outlined similar (? related) groups, as the pattern of assumed system. Versatility of the method allows to obtain result by any young specialist handled the pipettes and centrifuge for production of qualitative amplicons during polymerase chain reaction (PCR) and sequences. There is no need to hold in the hands object of research, the microtubes with samples of genomic DNA are quite enough. Could a problem of taxonomic structuring of biodiversity be solved by indoor specialists, do not go in nature and without assessment by highly skilled experts? Does it matter what taxonomic structure (system) for each group is proposed in the course of global biodiversity study? Can taxonomic problems be solved by new technology only? What trends are currently in studies of biodiversity and its structuring?

The author has tried to answer these questions by analyzing the existing database of entomological publications and outlining the trends in biodiversity investigation. The literature cited in the text does not claim to be exhaustive, the most characteristic (typical) papers are mentioned in present opinion.

\section{Main trends in the work of taxonomists. The methods used for the study of biodiversity and its structuring}

Analyzing the recently published work on this problem it could be recognized three main directions/trends in the world science by used tactical methods to achieve the strategic objectives on the inventory of biodiversity and its structuring.

The first direction corresponds to the quest for resolve of the accumulated taxonomic problems by molecular analysis of target DNA fragments. Now the most perfect tool is in the hands of scientists allowing not only accelerate the rate on assessment and inventory of biodiversity, but also able to solve the problems with the identification of species in those cases where the distinction by traditional morphological method is very difficult. It is well-known problems with the sibling or cryptic species, which are often, represent young and morphologically poorly diverged species, problems with association of males and females in species with strongly pronounced sexual dimorphism, problems with association conspecific specimens of different stages of development and different generations, etc. The great importance of this method for taxonomy is not in doubt, and modern taxonomy is not conceivable without molecular studies. 
However, should it recklessly describe new taxa based on some differences in the target DNA fragments only? Whether results of this study reflect the true diversity of taxonomic groups?

This debate is not new. The admonishment again the race for new taxa based on differences only in the target genome fragments were voiced in series of publications. The intraspecific and interspecific genetic divergency in different groups of insects and other invertebrates are characterized by very different performances. But more importantly, that genetic differences between populations within a species often exceed $2 \%$ (threshold commonly used to limit intraspecific variability or indicating the boundaries of the species) and overlap with genetic differences between congeneric species [2]. Thus, intraspecific variability of the nucleotide sequence of the mitochondrial gene COI, used for cataloging of biodiversity in frame of DNA barcoding programs, ranges from minimum $0.0 \%, 0.031 \%$, 0.077\%, $0.086 \%$ (Lepidoptera: Yponomeuta Latr., Eulamprotes Bradley, Papilio demoleus, Coleoptera: Blepharida, Diptera: Chrysomya, respectively) to $16.0 \%, 26.0 \%$ (Coleoptera: Dendroctonus, Phthiraptera: Columbicola, respectively) in representatives of different insect orders. At the same time the minimum interspecific divergences of closely related species are $0.19,1.5,1.7$ (Phthiraptera: Pediculus, Lepidoptera: Archips, Coleoptera: Trirhabda, respectively) [2-5]. Wide data overlap of intra- and interspecific divergence indicates the possibility of erroneous identity of species and subspecies and unreasonable increasing of some populations to the status of separate species. Thus, the reliability of species determination based on nucleotide sequence of COI can be extremely low and does not exceed $70 \%$, as indicated by Meier et al. [6], based on analysis of the various dipteran groups. On the other hand, increasing of some populations to the status of separate species will serve to crushing of Linnaean species, artificial increasing of taxonomic diversity. Probably it will be pertinent to recall here the situation well-known in the history of the taxonomy when the introducing of the "true species" (euspecies) jordanons, led to fragmenting of Linnean species into hundreds of units.

Summing up the views of researchers [7-11], it should be agreed with the dominant conclusion that the molecular method is undoubtedly a good tool to assessment and inventory of biodiversity and receiving signals stimulating to deep and comprehensive research of species diversity. However absolutisation of molecular method is unallowable, it cannot be regarded as a unique and versatile diagnostic method to confirmation (or denial) the status of separate species.

In general the practice of entomological research shows that ignorance of the actual number of species and hiding a complex of closely related species under single species are the temporary phenomenon, often based on a superficial, inadequate study not only the morphology and anatomy, but also features of the species ecology, conditions of development of the various stages, trophic links etc. From literature the received molecular signals on species diversification were soon confirmed in deeper comprehensive research of objects, or molecular data had confirmed the previously formed hypothesis of presence of new species [11-13]. This method is especially good for use in the taxonomy of morphologically uniform groups. As to most groups of insects, their morphology is an inexhaustible mine of information yet and unlikely it is required to be replaced by other source supposedly more informative. A striking proof of this is the recent discovery of new organs (glands of sexual segment) in such group as Lepidoptera [14], the anatomy of which seemingly exhaustively studied.
It seems very appropriate to bring here excerpts from the work Paul D.N. Hebert and T. Ryan Gregory [8]: "We emphasize that DNA barcoding seeks merely to aid in delimiting species-to highlight genetically distinct groups exhibiting levels of sequence divergence suggestive of species status. By contrast, DNA barcodes-by themselves-are never sufficient to describe new species".

Phylogenetic reconstruction and structuring of global biodiversity of insects are also not considered as destinations of DNA barcoding. But now we can see a series of papers in which phylograms are constructed based on analysis of nucleotide sequences COI. The attempts to remaking (remodelling) of system of studied groups on the basis of new phylograms, and the hastiness in the description of new taxa of different ranks often accompanied by very weak morphological arguments are looked premature. To date, there is a series of publications on different groups of invertebrates and vertebrates, in which the results of phylogenetic studies based on different genes, and sometimes on their complex, in many clusters perplex their authors by their unlikely from the viewpoint of morphological evolution [15-17].

The second direction of research of global biodiversity and its structuring is developed by that part of the world scientific community, which had experienced the euphoria from the apparent ease and produceability of obtaining of taxonomic developments based on molecular techniques, and faced with the problem of the impossibility of their interpretation. The comparison, such as the following, looks unambiguous and quite illustrative to above told: "It should come as no surprise that we urge a careful review of methods in modern molecular systematics when pumpkin pie can be shown to be the sister taxon to a crayfish with $100 \%$ bootstrap support" [18]. The calls for a return to traditional evolutionary morphology and constructions based on synapomorphies are in increasing frequency. It should be noted that scientists with a sufficiently conservative views also among followers of traditional morphological methods. Number of followers of this trend is indicative. According to the analysis of entomological publications on phylogenetic studies, the number of morphological articles exceeds both pure molecular and based on complex data [19].

The third direction in the biodiversity study is emerged relatively recently and its development is largely due to the specificity research object. Among the invertebrates including insects, there are groups with morphological homogeneity, or combination of characters belonging to different taxa is observed. Establishment of relationships, clarification of taxonomic position and rank for such groups are possible with an integrated approach, namely by involvement in the analysis not only morphological, but also molecular data. This approach corresponds to the new direction, developing in the modern science. However it is still in search and has not yet passed time testing.

Hence there are number of questions on used procedure in frame of this trend. It is well known that any morphological feature had been formed in the course of a long historical development of the ancestral form under the action of natural selection. The control over its development is often carried out not one, but several, and even complex interacting genes. Both morphological feature and nucleotide locus called a "character" by researchers; they are actually components of different levels of organization of life - molecular and organ or organism levels. It seems illogical and unacceptable the reduction of the latter to the former and the contrary, because the organ or organismal level, as higher level, is the system consisting of subsystems of lower levels (molecular, cellular and tissue), and at the same time 
the organ or organismal level represents a subsystem of high levels (the population-species, biogeocenotic and biosphere). However, the author deliberately leaves here beyond discussing the question of the legality of compounding into a single matrix morphological and molecular features non-equivalent inherently, but which are identified by researchers. The author focuses here attention on the integrated approach. Within framework of this trend the study of global biodiversity, its historical development, the genesis of recent forms are conducted using molecular method in combination with other methods approved for a long time - morphological, paleontological, ecological, embryological, histological, etc. This direction corresponds to the integrative taxonomy, the importance and necessity of that has already been discussed in a series of publications [10, 20]. Currently, this trend is presented until by a relatively small amount of work on certain groups of insects in the database of world entomological publications, in which both morphological and molecular genetic data are attracted to analysis [21-26].

\section{Significance of the biodiversity study and its structuring. Significance of experts in taxonomy}

Typically, the study of the species composition of any group, distributed in the region, preceded by the descriptive work and formation faunistic lists. Then it's time for more difficult and more skilled work on revision of studied groups, accompanied by the revealing of heterogeneous taxa, establishing phylogenetic relationships of the various groups and their position in the system. The results of phylogenetic and systematic work of taxonomists aimed at developing more elaborate system, not only reflecting the origin of one or another group and sequence of their divergence from the common trunk of development, but such system which has predictive properties.

In general, the work of highly skilled taxonomists, irreplaceable experts in their sphere, is directed namely at improving the predictive properties of the system of any group of insects, as well as all members of the animals. The results of their work have significant practical output and can be used successfully in the economics, in particular in its agricultural sector. This general proposition can be illustrated by the data of entomological research. Under the conditions of trend of climatic factors stable recorded in the present and the related dynamics of the species composition of entomofaunas of different regions it is traced the expansion of areas of southern and south eastern thermophilic species, often attributed to serious pests of agriculture and forestry. It is not only local, but worldwide problem. In particular, Ananarsia lineatella Zeller (the peach twig borer, Gelechiidae), Grapholita dimorpha Komai (Tortricidae) and Apocheima cinerarius (Erschov) (Geometridae) [27], which are serious pests, have also recently been recorded in the south of Primorsky Krai of the Russian Far East. All of them were not before recognized from Asian part of Russia. Accurate prediction of the biological properties of invasive species, the successful synthesis of biochemical substances (insecticides, pheromones), used to control their distribution and abundance are only possible with the use of advanced systems with taxonomic hierarchically subordinated monophyletic groups, in which the position of each species is scientifically based.

Thus, the natural system of any group, as a result of integrative taxonomy, grounded on a range of methods, will correspond with a pattern of divergence of monophyletic groups from the common trunk of historical development. This will significantly expand the theoretical importance of global biodiversity study. Ultimately, the scientific community will have not only quantitative data on the richness of wildlife (sometimes the aim of research is erroneously reduced only to that), but reconstructing of the main stages and features of development (genesis) biodiversity in different regions, scientific community will reveal regularities of organic evolution, that is important to predict the possible trend of ecosystem transformations.

\section{Conclusion}

Summarizing all the above, it should be concluded that the revolutionary negation of all experienced during a long course of science development will not lead to the triumph of knowledge. It seems that course of scientific development with continuity of achievements involving the most valuable ones and development of achieved things at a higher level would be more progressive. Same situation is with the new molecular method passing now wide approbation and located in finding the best markers for solving taxonomic problems. It has already been paid the deserved attention, and with time it can take its rightful place among equal methods which already had been tested by time. In general, the third direction in studies of global biodiversity based on an integrated approach and combines the use of both traditional morphological and new molecular method seems to be more promising. In view of this, the role of highly qualified experts, who know the morphological features and regularities of the historical development of a particular group, is indispensable in the study of biodiversity.

\section{Acknowledgements}

The study was conducted in frame of the projects FEB RAS 12-II0-06-019, 12-III-A-06-069, 12-III-A-06-078.

\section{References}

1. Foottit RG, Adler PH (Eds) (2009) Insect biodiversity: science and society. Blackwell Publishing Ltd. UK.

2. Cognato AI (2006) Standard percent DNA sequence difference for insects does not predict species boundaries. J Econ Entomol 99: 1037-1045.

3. Sperling FAH, Landry JF, Hickey DA (1995) DNA-Based Identification of Introduced Ermine Moth Species in North America (Lepidoptera: Yponomeutidae). Ann. Entomol. Soc. Am. 88 : 155-162.

4. Tsao WCh, Yeh WB (2008) DNA-Based Discrimination of Subspecies of Swallowtail Butterflies (Lepidoptera: Papilioninae) from Taiwan. Zoological Studies. 47 : 633-643.

5. Huemer P, Elsner G, Karsholt O (2013) Review of the Eulamprotes wilkella species-group based on morphology and DNA barcodes, with descriptions of new taxa (Lepidoptera, Gelechiidae). Zootaxa. 3746 : 069100.

6. Meier R, Shiyang K, Vaidya G, Ng PK (2006) DNA barcoding and taxonomy in Diptera: a tale of high intraspecific variability and low identification success. SystBiol 55: 715-728.

7. Hebert PD, Cywinska A, Ball SL, deWaard JR (2003) Biological identifications through DNA barcodes. ProcBiolSci 270: 313-321.

8. Hebert PD, Gregory TR (2005) The promise of DNA barcoding for taxonomy. SystBiol 54: 852-859.

9. Smith VS (2005) DNA barcoding: perspectives from a "Partnerships for Enhancing Expertise in Taxonomy" (PEET) debate. SystBiol 54: 841-844.

10. Will KW, Mishler BD, Wheeler QD (2005) The perils of DNA barcoding and the need for integrative taxonomy. SystBiol 54: 844-851.

11. Waugh J (2007) DNA barcoding in animal species: progress, potential and pitfalls. Bioessays 29: 188-197. 
Citation: Ponomarenko MG (2014) Global Biodiversity of Insects: Main Trends of Study, to the Question of Method and Importance of Research. J Biodivers Biopros Dev 1: 108. doi:10.4172/ijbbd.1000108

Page 4 of 4

12. Hebert PD, Penton EH, Burns JM, Janzen DH, Hallwachs W (2004) Ten species in one: DNA barcoding reveals cryptic species in the neotropical skipper butterfly Astraptesfulgerator. ProcNatlAcadSci U S A 101: 14812-14817.

13. Hebert PD, Stoeckle MY, Zemlak TS, Francis CM (2004) Identification of Birds through DNA Barcodes. PLoSBiol 2: e312.

14. Ponomarenko MG (2005) Gelechiid moths (Lepidoptera, Gelechiidae) of the Palaearctics: functional morphology of the male genitalia, phylogeny and taxonomy. Meeting in memory of NA Cholodkovsky $58: 1-139$ (In Russian).

15. Regier JC, Zwick A, Cummings MP, Kawahara AY, Cho S et.al. (2009) Toward reconstructing the evolution of advanced moths and butterflies (Lepidoptera: Ditrysia): an initial molecular study. BMC Evolutionary Biology 9: 280.

16. Mutanen M, Wahlberg N, Kaila L (2010) Comprehensive gene and taxon coverage elucidates radiation patterns in moths and butterflies. ProcBiolSci 277: 2839-2848.

17. Lecompte E, Denys C, Granjon L (2005) Confrontation of morphological and molecular data: the Praomys group (Rodentia, Murinae) as a case of adaptive convergences and morphological stasis. MolPhylogenetEvol 37: 899-919.

18. Randall DM, Gill AC (2010) Phylogenies without Synapomorphies - A Crisis in Fish Systematics: Time to Show Some Character. Zootaxa 2450: 26-40.

19. Bybee SM, Zaspel JM, Beucke KA, Scott CH, Smith BW, Branham MA (2010) Are molecular data supplanting morphological data in modern phylogenetic studies? Systematic Entomology 35: 2-5.

20. Sperling FAH, Roe A (2009) Molecular dimensions of Insect taxonomy In: Foottit RG, Adler PH (Eds) Insect biodiversity: science and society: 398-416.
21. Damgaard J, Sperling FAH (2001) Phylogeny of the water strider genus Gerris Fabricius (Heteroptera; Gerridae) based on COI mtDNA, EF-1alpha nuclear DNA and morphology. Systematic Entomology 26: 241-254.

22. Kruse JJ, Sperling FAH (2002) Phylogeny of Nearctic Species of the Xylosteana Group of Archips Hübner (Lepidoptera: Tortricidae) Based on Combined Analysis of Morphological and Mitochondrial DNA Data Sets. Annals of the Entomological Society of America. $95: 288-301$.

23. Zakharov EV, Caterino MS, Sperling FA (2004) Molecular phylogeny, historical biogeography, and divergence time estimates for swallowtail butterflies of the genus Papilio (Lepidoptera: Papilionidae). SystBiol 53: 193-215.

24. Wahlberg N, Braby MF, Brower AV, de Jong R, Lee MM, et al. (2005) Synergistic effects of combining morphological and molecular data in resolving the phylogeny of butterflies and skippers. ProcBiolSci 272: 1577-1586.

25. Mally R, Nuss M (2011) Molecular and morphological phylogeny of European Udea moths (Insecta: Lepidoptera: Pyraloidea). Arthropod Systematics \& Phylogeny. 69 : 55-71.

26. Léger T, Landry B, Nuss M2, Mally R2 (2014) Systematics of the Neotropical genus Catharylla Zeller (Lepidoptera, Pyralidae s. 1., Crambinae). Zookeys : 15-73.

27. Beljaev EA, Ponomarenko MG (2005) New Lepidopterological finds (Lepidoptera: Gelechiidae, Tortricidae, Geometridae) in South of Russian Far East. Far Eastern Entomologist. 155: 1-11. 